may closely simulate congenital heart disease, and the possibility of gross renal malformation with pulmonary hypoplasia should be

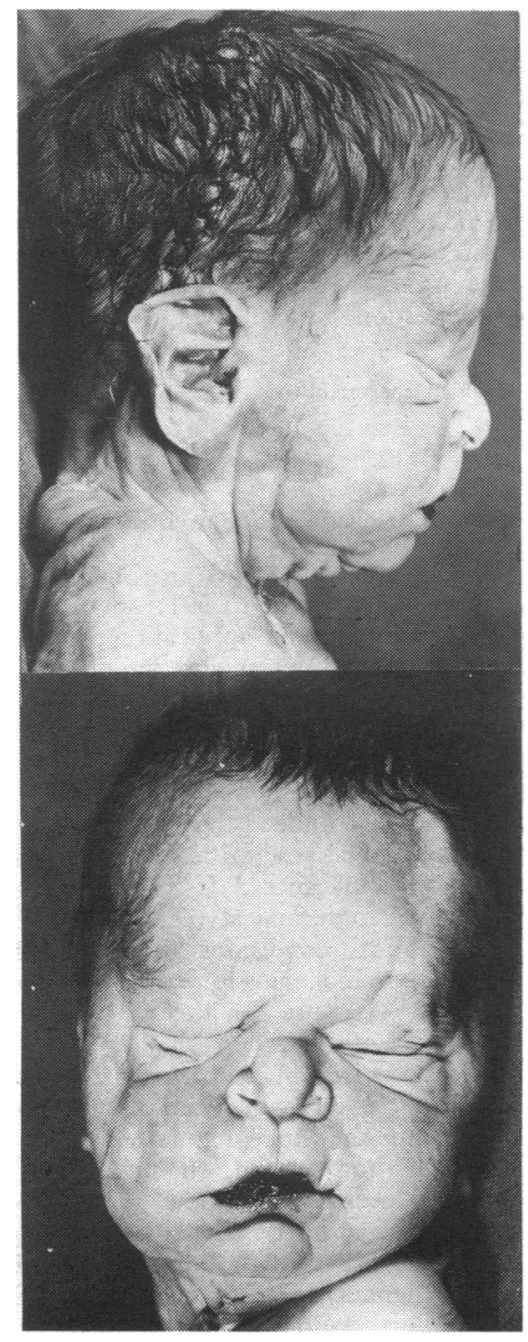

considered in the differential diagnosis of any atypical case of respiratory distress in the newborn period. Finally, we would like to emphasize the importance of routine necropsy in the newborn, particularly in the circumstances quoted above. Quite apart from the academic value of making a correct diagnosis, it may bring some comfort to parents to know that a renal malformation incompatible with long-term survival was present, particularly as it is most unusual for this abnormality to recur in a subsequent pregnancy.

We wish to thank Drs. B. R. Silk and C. J. E. Wynne-Williams, each of whom allowed us to report a case under their care and we are also grateful to Dr. R. A. Sladden for histological reports.-We are, etc.,

N. C. DE Northampton General Hospital, J. R. HARPER Northamp:on

1 Potter, E. L., American Youmal of Obstetrics and Gynecology, 1946, $51,885$.

Bain, A. D., and Scott, J. S., British Medical 3 Liberman, M. M., Abraham, J. M., and France, 4., 4 in.

4 Davidson, W. M.. and Ross, G. I. M., Yournal of Patho!osy and Bacteriolopy, 1954, 6., 459.

Miller, R. D., and Hamiton, W. R., Yourmal of the American Medical Association, 1969, 210,

\section{Immunological Control of Schistosomiasis}

SIR,-Your recent leading article (12 August, p. 366) outlined some of the interesting current research into immunological aspects of schistosomiasis. May I comment upon several points which I believe to be relevant?

Both epidemiological and experimental evidence indicate that some resistance to superinfection is developed, but as yet we have little information on how the immune responses in man are affected by the pattern of exposure to infection. Are the responses in localities where transmission is more or less perennial and at a relatively low level the same as in places where transmission is seasonal and often massive? Though heterologous immunity between different species of schistosomes has been demonstrated in experimental animals it is not a universal phenomenon. Double infections in man with Schistosoma haematobium and $S$. mansoni are common in many areas. In the Transvaal $S$. haematobium and the bovine $S$. mattheei occur together in man with evidence of hybridization and often in company with S. mansoni.1 In Cameroon S. haematobium and $S$. intercalatum occur together in at least two localities, again with possible evidence of hybridization.2 In parts of West Africa, Morocco, and Iran S. haematobium and $S$. bovis are often transmitted by the same species of snail at the same sites, and though in these cases there is no evidence of cross-infection between the human and cattle parasites there is at the same time nothing to suggest that there is any crossimmunity either. The human parasites may be non-pathogenic in cattle but infections of $S$. mansoni in calves are capable of reach ing maturity with the passage of viable eggs. Would it be an acceptable risk to introduce a pathogenic human parasite into an area where it might become established?

Schistosomiasis is a disease of rural areas, usually in countries with limited economic resources. The cost of schistosomiasis control based upon the use of expensive chemicals and drugs has already proved to be beyond the means of many of these countries, but rural improvement schemes involving the proper use of water resources are vital to their economy. The incorporation of environmental control measures into such development projects could lead to beneficial and lasting effects on the incidence of not only schistosomiasis but also other parasitic diseases. The eventual control of schistosomiasis will be in the hands of those who suffer from the disease. They will need guidance on how this can be achieved, but if the advice which is given is incompatible with local economic development it is likely to go unheeded. ${ }^{3}$ Already some pilot environmental control schemes are showing promis ing results. ${ }^{4}$ If, as you suggest, the people in endemic areas are becoming more sophisticated and are not prepared to tolerate parasitic infections this would seem to be an appropriate time to encourage the development of local environmental control schemes in association with the necessary elements of health education.

The construction of new irrigation schemes in endemic areas must include provision of adequate water facilities. both domestic and recreational, and proper consideration must be given to the siting of accommodation for the work force. The cost of attending to these details will normally be only a very small fraction of the total investment in the whole soheme ${ }^{6}$ and the neglect of such installations must be condemned as highly irresponsible. - I am, etc., Experimental Taxonomy Unit,
British Museum (Natural History) C. A. WRIGHT London S.W.7

1 Pitchford, R. J., Transactions of the Royal Society of Tropical Medicine and Hygiene, 1959, 53,

Wright, C. A., Southgate, V. R., and Knowles, Tropical Medicine and Hygiene, 1972, 66, 28 . Wright, C. A., Transactions of the Royal' Society
of Tropical Medicine and Hygiene, 1969, 63,

Pitchford, $\dot{R}$. J., South African Medical foumal, Barbosa, F. S., Pinto, R., and Souza, O. A Transactions of the Royal Society of Tropical Medicine and Hygiene, 1971, 65, 206

Arfaa, F.i Transactions of the Royal Society of 93.

\section{Ultrasound for Detecting Peristalsis}

SIR,-Ultrasonics offers a means of detecting postoperative recovery of bowel activity, and the following study, using a standard obstetric type of ultrasound device such as is used to detect the fetal heart beat, was done to compare the diagnostic value of ultrasound with that of using a stethoscope.

Sixty-seven patients were observed daily with both stethoscope and ultrasound after they had had an operation. The period of observation in each case was five minutes, and the postoperative day on which peristalsis was detected by each method was noted. In all the patients bowel movements were detected ultrasonically before they were heard by stethoscope. Peristalsis was detected on average 24 hours before bowel sounds were heard, and peristalsis was followed in 64 cases by the passage of faeces within 48 hours (see Fig.).

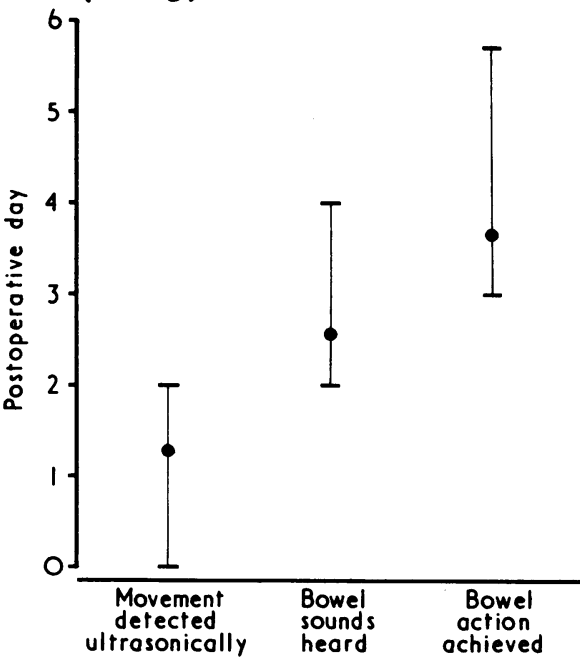

The same technique was used to monitor a case of ileus treated with neostigmine by the method of Neely and Catchpole.1 The neostigmine infusion was stopped when bowel movement was detected by ultrasound and this was five minutes before sounds were heard by stethoscope. The outcome was successful with a lower dose of neostigmine than would have been given if only auscultatory monitoring had been used.

A number of methods have been used to assess bowel motility, including intraluminal balloon manometry, ${ }^{2}$ pressure transducers, and radiotelemetry pills.' An external method using microphones (phonoenterography ${ }^{5}$ ) produces results which can be difficult to 
interpret. Ultrasound detects bowel movement because the bowel wall in peristalsis presents a moving interface which "modulates" the beam of ultrasound, which is then converted to sound. The results are qualitative but they provide the important information on whether bowel activity is present. The technique is easily applicable to convalescent patients, is simple to interpret, and in this series provided reliable and useful information. Ultrasound can be a useful additional tool in the assessment of the silent abdomen.-I am, etc.,

Westminster Hospital,

P. R. DAgGetT

1 Neely, J., and Catchpole, B. N., British foumal 1 Neely, J., and Catchpole,

2 Deller, D. J., and Wangel, A. G., Gastroenterology, 1965, 48, 45 .

Hightower, N. C., Federation Proceedings, 1952 4 Ramorino. M. L., and Colagrande, C., American 5 Wourmal of Digestive Diseases, 1964, 9, 64. 88.

\section{Cardiac Arrest with Clomipramine}

SIR, - Though convulsions and arrhythmias are well recognized complications of overdosage with tricyclic antidepressants cardiac arrest during therapeutic administration of these drugs has not previously been reported.

A 31-year-old woman was admitted to hospital suffering from severe depression with suicidal ideas. After careful screening, intravenous infusion therapy with clomipramine was started. Clomipramine $25 \mathrm{mg}$ in $250 \mathrm{ml} 5 \%$ dextrose was administered over a period of two and a half hours on the first day. The daily dose of clomipramine was gradually increased over 14 days to $250 \mathrm{mg}$. She received an infusion on five days a week and adequate oral therapy at the weekends. On the fifteenth day, while being infused with clomipramine $300 \mathrm{mg}$, the patient developed severe epileptic convulsions followed by cardiac arrest after she had received $170 \mathrm{mg}$ of clomipramine in 47 minutes. She was resuscitated with external cardiac massage by the nurse on duty before the cardiac arrest team arrived.

Immediately after resuscitation the patient had retrograde amnesia of a few hours, hyperreflexia, and signs of irritability. She was given a slow intravenous injections of diazepam $5 \mathrm{mg}$. An E.C.G. showed slight $T$ wave flattening. All drugs apart from diazepam orally were stopped. No abnormalities were noted, though her mental state deteriorated. After a week the patient was started on oral clomipramine and she began to improve. She was discharged six weeks later.

The cardiotoxic effects of tricyclic drugs have not received as much attention as their central nervous system manifestations. In animal experiments Cairncross and Gershon' found that small doses of imipramine increased the blood pressure and heart rate and that these were attributable to an anticholinergic effect. Experiments on isolated feline hearts and on canine hearts in situ showed that large doses of imipramine lessened myocardial contractability and cardiac output. Severe hypotension was reported secondary to decreased cardiac output. $^{2}$ These changes probably represent a direct toxic effect of the drug on the myocardium. In patients with a genetically slow rate of metabolism of tricyclic drugs these could gradually accumulate in such tissues as the lungs, heart, and brain until they exceed the epileptogenic threshold, resulting in convulsions and cardiac abnormalities.
I am grateful to Dr. C. J. S. Walter for his permission to report this case.-I am etc.

Princess Alerandra Hospital,
Harlow, Essex

G. SnNGH is likely to accelerate owing to meohanization and automation and when the capital cost of producing new jobs is increasing each year.

A country is overpopulated when it can maintain its present population only by means of an organization and structure that

1 Cairncross, K. D., and Gershon, S., Medical Fourmal of Australia, 1962, 2. 372.

of Pharmacology and Experimental Theraof Pharmacology, and

\section{Uganda Asians}

SIR,-Practitioners dealing with Uganda Asians after their arrival in Britain will be confronted with many diagnostic and therapeutic problems resulting from infection acquired overseas. These problems may be minimized by being aware of them, and the purpose of this letter is to assist towards that end.

Anticipation of malaria due to Plasmodium falciparum is of outstanding importance in that it may cause severe illness or death if not speedily diagnosed and treated. It is also, unfortunately, one of the easiest conditions to misdiagnose, often being thought to be an influenzal attack until delirium or cerebral manifestations supervene. It is recommended that Uganda Asians-like everyone else arriving in Britain from tropical Africashould be suspected of having malaria and have blood films examined if they develop pyrexia.

Other conditions which must also be borne in mind include alimentary and hepatic amoebiasis, schistosomiasis, and tuberculosis. Among these conditions hepatic amoebiasis is very frequently overlooked and pyrexia of obscure origin, particularly if associated with discomfort or tenderness over the liver, should be suspected of being caused by it

The staffs of the Hospital for Tropical Diseases, London (01-387 4411), the Liverpool School of Tropical Medicine (051-709 7611), and the Tropical Disease Unit, East Birmingham Hospital (021-772 4311) will readily give help where needed.-I am, etc.,

Hospital for Tropical Diseases,
London N.W.1

A. W. WOODRUFF

\section{Overpopulation}

SIR,-Your leading article (19 August, p. 432) raises the question, What is overpopulation? I think I may be able to help you.

A country (Britain) is overpopulated when its population density is the third highest in the world and when, in the case of England with a population density 920 per square mile $\left(2.5 \mathrm{~km}^{2}\right)$, it is the most densely populated country in the world.

A country is overpopulated when it produces only half its food and animal feeding stuffs and has to import and pay for the rest by exporting manufactured goods against fierce and increasing international competition to countries which are themselves becoming industrialized and which will soon no longer require our exports.

A country is overpopulated when there are one million unemployed, when the number of jobs is declining rapidly, and when the excess of births over deaths represents 700 new jobs every day. This is particularly relevant when the decline in the number of is so complex and dependent on sophisticated energy systems that small groups of workers can in a matter of two to three weeks, by withholding their labour, bring the country to the point of collapse, as has been clearly demonstrated by the power workers' strike and the miners' strike. Our vulnerability is beyond question.-I am, etc.

R. D. HaIgh

City Health Department,
Lincoln

\section{Toxicity of Podophyllum}

SIR,-The paper of Dr. M. J. Chamberlain and others (12 August, p. 391) on the toxic effect of podophyllum application in pregnancy is of great interest and importance to those of us confronted with the problem of treating genital warts, an infection which appears to be of increasing prevalence.

As the authors point out, podophyllum is cytotoxic. It has indeed been shown, with some of its derivatives, to be of value in the treatment of skin cancer. ${ }^{1}$ It may, moreover, itself produce epidermal atypia, though under ordinary clinical conditions it is probably not frankly carcinogenic, in vulval warts and the cervix. ${ }^{23}$ Its use in the treatment of warts, even when used in smaller amounts which are washed off within a few hours, on less florid lesions which are not haemorrhagic and in the non-pregnant patient, is certainly open to question, ${ }^{2}$ the more so as its effectiveness seems inconstant and at best several paintings may be needed.

However, genital warts may on occasion become malignant, a recent and well-authenticated report being that of Oriel and Whimster, ${ }^{4}$ and they certainly commonly cause a great deal of inconvenience. Diathermy usually involves admis ion to hospital and a general aneesthetic. Cryosurgerys may also be unpleasant for the patient. Even more than in the case of non-genital viral warts there is great need of a treatment both simple and effective.-I am, etc.

C. M. RIDLEY

Elizabeth Garrett Anderson Hospital,

London N.W.1

1 Bettley, F. R., British fournal of Dermatology, 1971, 84, 74. Liu, G. T., and Emrich, J. P., Fournal of Reproductive Medicine, 1971, 6, 159 . Kaminetzky, H. A., and Swerdlow, M., American
Yournal of Obstetrics and Gynecology, 1965, 93, 486.

4 Oriel, J. D., and Whimster, I. W., British Youmal 4 Oriel, J. D., and Whimster, I. W., British Youmal
of Dermatology, 1971, 84, 71.
5 Ostergard, D. R., and Townsend, D. E., Cryobiology, 1969, 5, 340 .

SIR,-We wish to make a few comments on the article by Dr. M. J. Chamberlain and o'hors (12 August, p. 391). They do not state whether vaginal warts were also present and required painting. The presence of an untreated vaginitis could account for rapid absorption of podophyllum.

We do not use podophyllum in the first three months of pregnancy and thereafter with circumspection. The treatment of only a 